\title{
Usefulness of Neutrophil to Lymphocyte Ratio in Prediction of Coronary Artery Lesions in Patients with Kawasaki Disease
}

\author{
Fikri Demir ${ }^{1}$, Cem Karadeniz ${ }^{2}$, Rahmi Özdemir², Y1lmaz Yozgat ${ }^{2}$, Kübra Çelegen ${ }^{3}$, Utku Karaaslan ${ }^{3}$, \\ Mustafa Demirol ${ }^{2}$, Timur $\mathrm{Meşe}^{2}$, Nurettin Ünal ${ }^{2}$
}
${ }^{1}$ Department of Pediatric Cardiology, Dicle University Faculty of Medicine, Diyarbakır, Turkey
${ }^{2}$ Department of Pediatric Cardiology, Behçet Uz Children's Hospital, İzmir, Turkey
${ }^{3}$ Department of Pediatrics, Behçet Uz Children's Hospital, İzmir, Turkey

Background: Kawasaki disease is an inflammatory condition. Neutrophil to lymphocyte ratio is a marker reflecting inflammation.

Aims: The aim of the study is to evaluate usefulness of neutrophil to lymphocyte ratio in diagnosis of Kawasaki disease and in prediction of coronary artery lesions. Study Design: Retrospective cross-sectional study. Methods: Seventy-five children with Kawasaki disease and 66 controls were retrospectively enrolled. Their leukocyte, neutrophil, and lymphocyte counts were recorded. Abnormally distributed data were shown as median (interquartile range). Cases having coronary artery diameter two standard deviation above mean were diagnosed to have coronary artery lesions.

Results: Median age of Kawasaki disease patients was 34 months. Twentyfive of those (33.33\%) had incomplete Kawasaki disease and twenty-six (34.66\%) had coronary artery lesions. Leukocyte [12.61 (6.09)x103/ $\mu \mathrm{L}$ vs. $\left.8.48(5.58) \times 10^{3} / \mu \mathrm{L}\right]$, neutrophil [6.73 (4.10) $\mathrm{x} 10^{3} / \mu \mathrm{L}$ vs. $\left.4.62(5.47) \times 10^{3} / \mu \mathrm{L}\right]$, and lymphocyte [4.04
(2.91) $\times 10^{3} / \mu \mathrm{L}$ vs. $\left.3.02(2.57) \times 10^{3} / \mu \mathrm{L}\right]$ counts were significantly higher in Kawasaki disease patients compared to controls (all p values $<0.01$ ). However, there was not significant difference between patients and controls regarding neutrophil to lymphocyte ratio [1.72 (1.22) vs. 1.71 (1.88)]. Findings of Kawasaki disease and incomplete Kawasaki disease cases did not differ, while comparison of patients with and without coronary artery lesions revealed significantly higher neutrophil to lymphocyte ratio values in former group [2.02 (1.63) vs. 1.50 (1.28), $\mathrm{p}=0.01$ ]. The cut-off neutrophil to lymphocyte ratio value for prediction of coronary artery lesions was determined as 1.32 .

Conclusion: Neutrophil to lymphocyte ratio values in Kawasaki patients with coronary lesions were significantly higher than the ones without and values greater than 1.32 were useful in prediction of coronary lesions. Keywords: Coronary aneurysm, Kawasaki disease, lymphocytes, neutrophils
Kawasaki disease (KD) is a systemic febrile condition leading to the inflammation of vessels including coronary arteries (1). Coronary artery aneurysms, occuring in approximately $15-25 \%$ of the patients, are the most important and life-threatening complication of KD (2). KD mainly affects children younger than five years old. Although it has been known for years, the etiology of the disease remains largely unexplained $(3,4)$.

Due to the lack of specific tools, the diagnosis of KD is still based on clinical features. At least four of the following five

Address for Correspondence: Dr. Fikri Demir, Department of Pediatric Cardiology, Dicle University Faculty of Medicine, Diyarbakır, Turkey Phone: +90 5326937390 e-mail: fikridemir@yahoo.com

Received: 24.12.2014 Accepted: 27.04.2015 • DOI: 10.5152/balkanmedj.2015.151108

Available at www.balkanmedicaljournal.org

Cite this article as:

Demir F, Karadeniz C, Özdemir R, Yozgat Y, Çelegen K, Karaaslan U, et al. Usefulness of neutrophil to lymphocyte ratio in prediction of coronary artery lesions in patients with Kawasaki disease.

Balkan Med J 2015;32:371-6. 
clinical criteria together with fever lasting equal to or longer than five days should be present for the diagnosis: bilateral non-purulent conjunctivitis; extremity findings including erythema and/or indurative edema on the hands and feet, and membranous desquamation starting in the periungual regions; changes in the lips and oral cavity; polymorphous exanthema; and cervical lymphadenopathy (usually unilateral with a diameter of $1.5 \mathrm{~cm}$ or more). However, those patients with prolonged fever ( $\geq 5$ days) together with two or three clinical criteria may be diagnosed as incomplete $\mathrm{KD}$ in the presence of some supplemental laboratory findings (5). It has been reported increasingly in recent years, especially among young infants and children. Because incomplete $\mathrm{KD}$ also results in coronary artery lesions (CALs), it should be diagnosed promptly $(5,6)$. However, the diagnosis is still difficult and further laboratory studies are needed.

Neutrophil to lymphocyte ratio (NLR) is a novel parameter, studied in the conditions with inflammatory pathogenesis including ischemic heart disease, stroke, and infections (7-9). It was reported to be a strong predictor of adverse cardiovascular outcome and severity of coronary artery ectasia in adult population (10-12).

In this study, the usefulness of NLR in the diagnosis of KD or incomplete KD and the correlation between NLR and the presence of coronary artery lesions were evaluated. The usefulness of NLR has not been studied in patients with KD so far.

\section{MATERIALS AND METHODS}

Seventy-five children diagnosed with Kawasaki disease and 66 age- and sex-matched controls with upper respiratory tract infection-related fever between 2005 and 2013 were retrospectively enrolled in the study. White blood cell (WBC), neutrophil, and lymphocyte counts, erythrocyte sedimentation rate (ESR) and C-reactive protein (CRP) values of the cases and controls were collected from computerized patient database. The values of the patients obtained at the time of diagnosis of Kawasaki disease (5 to 9 days after occurrence of fever) were evaluated and compared with those of controls measured during the assessment of upper respiratory tract infection. The study was approved by the ethical committee of Behçet $\mathrm{Uz}$ Children's Hospital.

The diagnosis was established in patients who fulfilled the diagnostic criteria of KD. Those cases who had prolonged fever ( $\geq 5$ days) and 2 or 3 principal clinical criteria together with echocardiographic detection of coronary artery abnormalities or at least three of supplemental laboratory findings including hypoalbuminemia $(<3 \mathrm{~g} / \mathrm{dL})$, anemia, elevation of alanine aminotransferase, thrombocytosis $\left(>450,000 / \mathrm{mm}^{3}\right.$, after 7 days), leukocytosis $\left(>15,000 / \mathrm{mm}^{3}\right)$, and sterile pyuria ( $>10$ white blood cells/high-power field) were diagnosed as incomplete KD.

A Vivid 3 Ultrasound System (GE Medical Systems, Waukesha, WI, USA), with 3 and $5 \mathrm{MHz}$ transducers was used for the assessment of coronary artery lesions. The procedure was performed before intravenous immunoglobulin administration. The cases who had coronary arteries with an internal diameter two standard deviations above the mean adjusted for body surface area were diagnosed as having CALs which included ectasia and/or aneurysm.

Data were analyzed with the SPSS 18.0 statistical package program (SPSS Inc., Chicago, Illinois, USA). The distribution pattern of data was assessed by the Kolmogorov-Smirnov test. Normally distributed quantitative variables were demonstrated as mean \pm standard deviation, while the median and interquartile range were chosen for abnormally distributed data. Chi-square test or Fisher's exact test were used to compare the qualitative data. The differences between the quantitative groups with normal distribution were evaluated with the Student's t-test. The Mann-Whitney U test was used for abnormally distributed variables. A receiver operator characteristic (ROC) curve was constructed for NLR to determine a cut-off value for the prediction of coronary artery lesions. Sensitivity and specificity were calculated according to the highest Youden index. A $p$ value of $<0.05$ was considered statistically significant.

\section{RESULTS}

The median age of 75 Kawasaki disease patients at admission was 34 months (range: 4-140 months). Twenty-five of those (33.33\%) had incomplete KD and twenty-six (34.66\%) had coronary involvement. The characteristics of the patients and controls were shown in Table 1. White blood cell, neutrophil, lymphocyte, and platelet counts were found to be significantly higher, and conversely, hemoglobin levels were determined to be statistically lower in patients with KD compared to controls (all $p$ values $<0.01$ ). However, there was no significant difference between the patient and control groups in terms of NLR.

There was no significant difference between the clinical and laboratory findings of cases with $\mathrm{KD}$ and incomplete $\mathrm{KD}$ (Table 2), whereas a comparison of the findings of patients with and without CALs revealed a significantly higher neutrophil count, NLR, and CRP levels in the former group (Table 3).

ROC analysis revealed an area under the curve value of 0.67 $(p=0.008)$ (Figure 1). The cut-off NLR value for the prediction of coronary artery lesions was determined to be 1.32 with a 
TABLE 1. The characteristics of patients and controls

\begin{tabular}{lccc}
\hline & $\begin{array}{c}\text { Patients } \\
(\mathrm{n}=75)\end{array}$ & $\begin{array}{c}\text { Controls } \\
(\mathrm{n}=66)\end{array}$ & $\begin{array}{c}\mathrm{p} \\
\text { value }\end{array}$ \\
\hline Age at diagnosis (months)* & $34(46)$ & $24(51)$ & $\mathrm{NS}$ \\
Gender (male/female) & $46 / 29$ & $40 / 26$ & $\mathrm{NS}$ \\
WBC count $\left(\mathrm{x} 10^{3} / \mu \mathrm{L}\right) *$ & $12.61(6.09)$ & $8.48(5.58)$ & $<0.001$ \\
Neutrophil count $\left(\mathrm{x} 10^{3} / \mu \mathrm{L}\right) *$ & $6.73(4.10)$ & $4.62(5.47)$ & $<0.001$ \\
Lymphocyte count $\left(\mathrm{x} 10^{3} / \mu \mathrm{L}\right) *$ & $4.04(2.91)$ & $3.02(2.57)$ & $<0.01$ \\
NLR* & $1.72(1.22)$ & $1.71(1.88)$ & $\mathrm{NS}$ \\
Platelet count $\left(\mathrm{x} 10^{3} / \mu \mathrm{L}\right) *$ & $468(363)$ & $306(158)$ & $<0.001$ \\
Hemoglobin $(\mathrm{gr} / \mathrm{dL})^{\S}$ & $10.53 \pm 1.22$ & $11.80 \pm 1.38$ & $<0.001$ \\
\hline *: Data presented as median (interquartile range); $\$$ : Data presented as mean \pm standard \\
deviation.
\end{tabular}

TABLE 2. The comparison of the findings of Kawasaki disease and incomplete Kawasaki disease patients

\begin{tabular}{lccc}
\hline & $\begin{array}{c}\mathrm{KD} \\
(\mathrm{n}=50)\end{array}$ & $\begin{array}{c}\text { Incomplete KD } \\
(\mathrm{n}=25)\end{array}$ & $\begin{array}{c}\mathrm{p} \\
\text { value }\end{array}$ \\
\hline Age at diagnosis (months)* & $38(48)$ & $28(29)$ & $\mathrm{NS}$ \\
Gender (male/female) & $31 / 19$ & $15 / 10$ & $\mathrm{NS}$ \\
WBC $\left(\mathrm{x} 10^{3} / \mu \mathrm{L}\right)^{*}$ & $13.46(6.98)$ & $12.22(5.91)$ & $\mathrm{NS}$ \\
Neutrophil count $\left(\mathrm{x} 10^{3} / \mu \mathrm{L}\right)^{*}$ & $6.72(4.40)$ & $6.53(4.03)$ & $\mathrm{NS}$ \\
Lymphocyte count $\left(\times 10^{3} / \mu \mathrm{L}\right)^{*}$ & $4.11(2.88)$ & $3.70(2.61)$ & $\mathrm{NS}$ \\
NLR* & $1.53(1.37)$ & $1.88(0.94)$ & $\mathrm{NS}$ \\
Platelet count $\left(\mathrm{x} 10^{3} / \mu \mathrm{L}\right)^{*}$ & $462(365)$ & $496(407)$ & $\mathrm{NS}$ \\
Hemoglobin $(\mathrm{gr} / \mathrm{dL})^{\S}$ & $10.52 \pm 1.26$ & $10.50 \pm 1.29$ & $\mathrm{NS}$ \\
CRP (mg/dL)* & $2.83(5.87)$ & $2.80(3.92)$ & $\mathrm{NS}$ \\
ESR (mm/hour)* & $95.00(42.00)$ & $79.00(53.00)$ & $\mathrm{NS}$ \\
Presence of CALs (n (\%)) & $16(32 \%)$ & $10(40 \%)$ & NS \\
\hline *: Data presented as median (interquartile range); ${ }^{\S}$ : Data presented as mean \pm standard \\
deviation. & & \\
CALs: coronary artery lesions; CRP: C-reactive protein; ESR: erythrocyte sedimen- \\
tation rate; KD: Kawasaki disease; n: number; NLR: neutrophil to lymphocyte ratio; \\
WBC: white blood cell; NS: not significant
\end{tabular}

sensitivity of $92.3 \%$ (95\% CI 74.9-99.1) and a specificity of $38.8 \%$ (95\% CI 25.2-53.8).

\section{DISCUSSION}

Kawasaki disease is an inflammatory condition which may result in coronary artery lesions. Because of the possibility of this life-threatening complication, timely and accurate diagnosis of KD is important. Despite some established diagnostic clinical criteria, the diagnosis of incomplete $\mathrm{KD}$ is still challenging $(1,2,5)$. The current study evaluated the usefulness of NLR in the diagnosis of KD and prediction of its outcomes and found that higher NLR values, especially those greater
TABLE 3. The features of Kawasaki patients with and without coronary involvement

\begin{tabular}{lccc}
\hline & $\begin{array}{c}\text { Patients without } \\
\text { CALs }(\mathrm{n}=49)\end{array}$ & $\begin{array}{c}\text { Patients with } \\
\text { CALs }(\mathrm{n}=26)\end{array}$ & $\begin{array}{c}\mathrm{p} \\
\text { value }\end{array}$ \\
\hline Age at diagnosis (months) & $36(44)$ & $31(44)$ & $\mathrm{NS}$ \\
Sex (male/female) & $27 / 22$ & $19 / 7$ & $\mathrm{NS}$ \\
WBC count $\left(\mathrm{x} 10^{3} / \mu \mathrm{L}\right)$ & $12.40(6.11)$ & $13.93(7.01)$ & $\mathrm{NS}$ \\
Neutrophil count $\left(\mathrm{x} 10^{3} / \mu \mathrm{L}\right)$ & $6.21(4.00)$ & $7.91(5.23)$ & 0.02 \\
Lymphocyte count $\left(\mathrm{x} 10^{3} / \mu \mathrm{L}\right)$ & $4.02(3.02)$ & $3.80(2.38)$ & $\mathrm{NS}$ \\
NLR & $1.50(1.28)$ & $2.02(1.63)$ & 0.01 \\
Platelet count $\left(\mathrm{x} 10^{3} / \mu \mathrm{L}\right)$ & $456(331)$ & $516(380)$ & $\mathrm{NS}$ \\
Hemoglobin $(\mathrm{gr} / \mathrm{dL})$ & $10.52(1.29)$ & $10.53(1.04)$ & $\mathrm{NS}$ \\
CRP $(\mathrm{mg} / \mathrm{dL})$ & $2.02(4.61)$ & $3.60(8.18)$ & 0.02 \\
ESR $(\mathrm{mm} / \mathrm{hour})$ & $81.00(62.00)$ & $91.00(34.00)$ & $\mathrm{NS}$ \\
\hline All &
\end{tabular}

All data presented as median (interquartile range). CALs: coronary artery lesions; CRP: C-reactive protein; ESR: erythrocyte sedimentation rate; n: number; NLR: neutrophil to lymphocyte ratio; WBC: white blood cell; NS: not significant

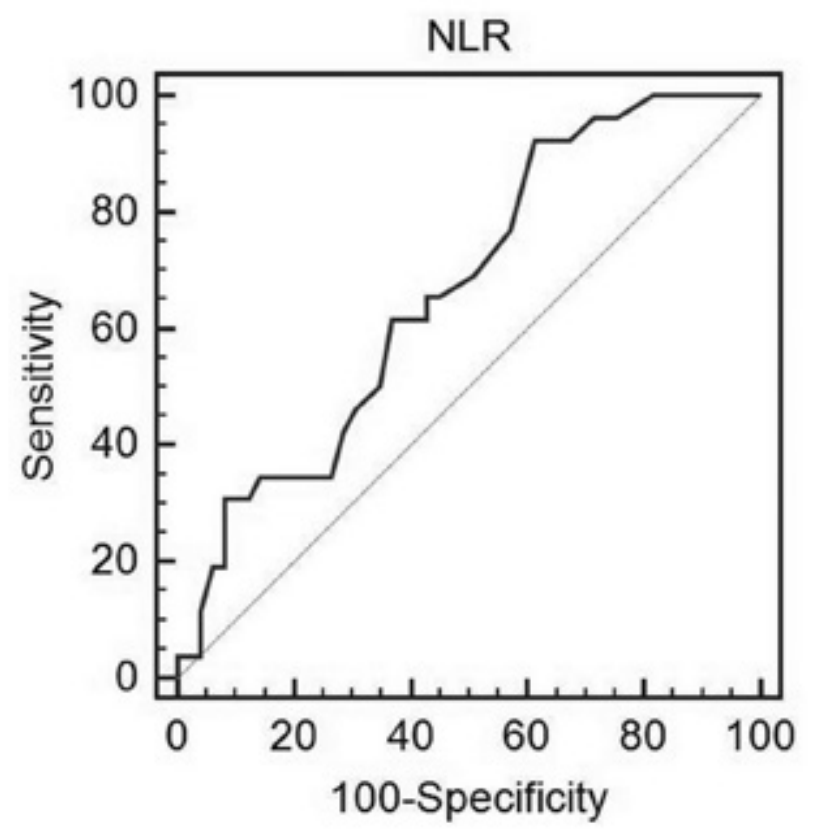

FIG. 1. ROC curve for neutrophil-to-lymphocyte ratio

than 1.32 , were found to be valuable in the prediction of coronary lesions.

Previous studies have shown some correlations between inflammation markers and cardiovascular diseases. CRP is the most extensively studied inflammatory marker $(13,14)$. Increased WBC count is a simple and useful parameter which was found to be an independent risk factor for major cardiovascular diseases. It was also reported to be associated with the severity of coronary artery lesions $(13,15)$. In recent years, there has been a focus on white blood cell subtypes such as neutrophil, lymphocyte, and neutrophil to lymphocyte ratio as 
the predictors of cardiovascular risk. NLR may be more preferable in this manner owing to two factors: Firstly, although some conditions such as exercise and dehydration may increase the absolute number of neutrophils and lymphocytes, NLR is less commonly affected; Second, and more importantly, it is a ratio calculated from the counts of products of two different but complementary immune pathways (12). Neutrophils are effective in ongoing active non-specific inflammation through the secretion of various inflammatory enzymes and mediators including elastase, myeloperoxidase, and freeoxygen radicals. In contrast to the phagocytic and killing effects of neutrophils, lymphocytes fulfill the regulatory function of the immune system (12,16-18). Increased neutrophil count was found to be associated with infarct size and adverse angiographic outcomes in patients with myocardial infarction $(12,19,20)$, while low lymphocyte count was related to adverse outcomes in patients with myocardial infarction and chronic heart failure $(12,21,22)$. Since NLR reflects both immune pathways and is probably less affected by confounding conditions, it may be more predictive than either parameter alone (12).

Kawasaki disease is a condition that may result in coronary abnormalities. The inflammatory process persists in the walls of medium- and large-sized arteries as pan-arteritis and coronary arteries are frequently affected. Subendothelial edema and mononuclear cellular infiltration accompany arteritis (23). As a consequence, internal elastic lamina is disrupted and myointimal proliferation occurs. Vascular smooth muscle cells become necrotic due to the release of matrix metalloprotease from the medial layer. These destructive changes lead to excessive fibrosis and aneurysm formation. Histopathological studies have revealed that lesions in the initial stages of inflammation contain not only macrophages and lymphocytes but also neutrophils. This finding indicates that both neutrophils and lymphocytes are involved in the initial damage to arterial walls. The levels of cytokines such as interleukin (IL)6 and tumor necrosis factor (TNF)- $\alpha$ were found to be higher in the acute phase of KD as well $(24,25)$.

In the current study, although we found higher WBC, neutrophil, and lymphocyte counts in patients with KD compared to the control group with upper respiratory tract infection-related fever, we did not determine any difference in terms of NLR. This means that NLR is not helpful in the differentiation of Kawasaki disease from other febrile conditions. NLR seems not to be effective in the discrimination of KD and incomplete $\mathrm{KD}$ as well. However, neutrophil to lymphocyte ratios were found to be higher in Kawasaki disease patients with CALs than those without and the cut-off value associated with an increased probability of coronary lesions was determined to be 1.32 . The reasons for these findings remain unex- plained. Incomplete Kawasaki disease patients are reported to be associated with an increased risk of CALs (26). However, no significant difference was determined between $\mathrm{KD}$ and incomplete KD groups in terms of the presence of CALs in our study. The findings that none of the markers changed between $\mathrm{KD}$ and incomplete KD patients might have resulted from the similar severity of both inflammatory conditions.

Neutrophil to lymphocyte ratio has not been studied in cases with Kawasaki disease so far. However, some investigations assessing the role of inflammation in adult patients with coronary artery ectasia were conducted, and these studies reported higher levels of serum (IL)- 6 and (TNF)- $\alpha$, together with the accumulation of inflammatory cells in the medial layer of coronary arteries (27-29). Some other studies additionally found higher neutrophil to lymphocyte ratios in patients with coronary artery ectasia than in healthy controls, and they denoted that neutrophils cause important changes in vascular tissue by release of elastase, myeloperoxidase, free-oxygen radicals, and various hydrolytic enzymes $(11,30)$. The KD cases with CALs probably have more severe inflammation, so markers such as NLR, neutrophil count, and CRP differed significantly in our population. This statement was supported by the study of Sarli et al. (11), who found that NLR was associated with the severity of coronary artery ectasia in their adult patients. They compared their cases with healthy controls. Nevertheless, our patients were compared with KD patients with inflammation but no CALs and NLR was found to be still useful in prediction of the development of coronary lesions.

The finding that increased NLR, especially values greater than 1.32 , is associated with the presence of CALs may be important for the identification of KD cases at risk of coronary lesions. Therefore, more aggressive anti-inflammatory therapy including repeated-dose of intravenous immunoglobulin and high-dose acetyl salycilic acid with a longer duration can be ordered, and more intense echocardiographic follow-up may be scheduled.

This study has some limitations that need to be considered. The numbers of our incomplete Kawasaki patients and cases with CALs were relatively low. The presence of coronary artery lesions was evaluated, but not the severity or morphologic characteristics of them owing to the retrospective nature of the study. Area under the curve in ROC analysis and specificity of NLR cut-off values were found to be low, possibly because of the relative paucity of cases with CALs.

In conclusion, NLR values in Kawasaki patients with coronary lesions were found to be significantly higher than those without and values greater than 1.32 were useful in the prediction of CALs. However, NLR was not valuable in the differentiation of KD and incomplete KD. To the best of our knowledge, the current study was the first to investigate the 
usefulness of NLR in the evaluation of patients with Kawasaki disease.

Ethics Committee Approval: Ethics committee approval was received for this study from the ethics committee of Behçet Uz Children's Hospital.

Informed Consent: An informed consent was obtained from the parents of all the participants.

Peer-review: Externally peer-reviewed.

Author contributions: Concept - F.D., C.K., R.Ö.; Design - F.D., C.K., R.Ö.; Supervision - T.M., N.Ü.; Resource - Y.Y., K.Ç., M.D.; Materials - Y.Y., K.Ç., M.D.; Data Collection \&/or Processing - F.D., C.K., R.Ö., U.K.; Analysis \&/or Interpretation - F.D., C.K., R.Ö., U.K.; Literature Search - F.D., C.K., R.Ö.; Writing - F.D., C.K., R.Ö.; Critical Reviews - Y.Y., T.M., N.Ü.

Conflict of Interest: No conflict of interest was declared by the authors.

Financial Disclosure: The authors declared that this study has received no financial support.

\section{REFERENCES}

1. Kawasaki T, Kosaki F, Okawa S, Shigematsu I, Yanagawa H. A new infantile acute febrile mucocutaneous lymph node syndrome (MLNS) prevailing in Japan. Pediatrics 1974;54:271-6.

2. Kato H, Ichinose E, Yoshioka F, Takechi T, Matsunaga S, Suziki $\mathrm{K}$, et al. Fate of coronary aneurysms in Kawasaki disease: serial coronary angiography and long-term follow-up study. $A m J$ Cardiol 1982;49:1758-66. [CrossRef]

3. Huang WC, Huang LM, Chang IS, Chang LY, Chiang BL, Chen PJ, et al. Epidemiologic features of Kawasaki disease in Taiwan, 2003-2006. Pediatrics 2009;123:e401-5. [CrossRef]

4. Nakamura Y, Yashiro M, Uehara R, Oki I, Kayaba K, Yanagawa H. Increasing incidence of Kawasaki disease in Japan: nationwide survey. Pediatr Int 2008;50:287-90. [CrossRef]

5. Newburger JW, Takahashi M, Gerber MA, Gewitz MH, Tani LY, Burns JC, et al. Diagnosis, treatment and long-term management of Kawasaki disease: a statement for health professionals from the Committee on Rheumatic Fever, Endocarditis and Kawasaki Disease, Council on Cardiovascular Disease in the Young, American Heart Association. Circulation 2004;110:2747-71. [CrossRef]

6. Perrin L, Letierce A, Guitton C, Tran TA, Lambert V, Kone-Paut I. Comparative study of complete versus incomplete Kawasaki disease in 59 pediatric patients. Joint Bone Spine 2009;76:481-5. [CrossRef]

7. Bhat T, Teli S, Rijal J, Bhat H, Raza M, Khoueiry G, et al. Neutrophil to lymphocyte ratio and cardiovascular diseases: a review. Expert Rev Cardiovasc Ther 2013;11:55-9. [CrossRef]
8. Gökhan S, Ozhasenekler A, Mansur Durgun H, Akil E, Ustündag M, Orak M. Neutrophil lymphocyte ratios in stroke subtypes and transient ischemic attack. Eur Rev Med Pharmacol Sci 2013; 17:653-7.

9. Yoon NB, Son C, Um SJ. Role of the neutrophil-lymphocyte count ratio in the differential diagnosis between pulmonary tuberculosis and bacterial community-acquired pneumonia. Ann Lab Med 2013;33:105-10. [CrossRef]

10. Gibson PH, Croal BL, Cuthbertson BH, Small GR, Ifezulike AI, Gibson G, et al. Preoperative neutrophil-lymphocyte ratio and outcome from coronary artery bypass grafting. Am Heart $J$ 2007;154:995-1002. [CrossRef]

11. Sarli B, Baktir AO, Saglam H, Arinc H, Kurtul S, Sivgin S, et al. Neutrophil-to-Lymphocyte Ratio is Associated With Severity of Coronary Artery Ectasia. Angiology 2014;65:147-51. [CrossRef]

12. Azab B, Zaher M, Weiserbs KF, Torbey E, Lacossiere K, Gaddam $\mathrm{S}$, et al. Usefulness of neutrophil to lymphocyte ratio in predicting short- and long-term mortality after non-ST-elevation myocardial infarction. Am J Cardiol 2010;106:470-6. [CrossRef]

13. Ates AH, Canpolat U, Yorgun H, Kaya EB, Sunman H, Demiri E, et al. Total white blood cell count is associated with the presence, severity and extent of coronary atherosclerosis detected by dual-source multislice computed tomographic coronary angiography. Cardiol J 2011;18:371-7.

14. Danesh J, Collins R, Appleby P, Peto R. Association of fibrinogen, C-reactive protein, albumin, or leukocyte count with coronary heart disease: meta-analyses of prospective studies. JAMA 1998;279:1477-82. [CrossRef]

15. Lee CD, Folsom AR, Nieto FJ, Chambless LE, Shahar E, Wolfe DA. White blood cell count and incidence of coronary heart disease and ischemic stroke and mortality from cardiovascular disease in African-American and White men and women atherosclerosis risk in communities study. Am J Epidemiol 2001;154:758-64. [CrossRef]

16. Mehta J, Dinerman J, Mehta P, Saldeen TG, Lawson D, Donnelly WH, et al. Neutrophil function in ischemic heart disease. Circulation 1989;79:549-56. [CrossRef]

17. Baldus S, Heeschen C, Meinertz T, Zeiher AM, Eiserich JP, Munzel T, et al. Myeloperoxidase serum levels predict risk in patients with acute coronary syndromes. Circulation 2003;108:14. [CrossRef]

18. Hansen PR. Role of neutrophils in myocardial ischemia and reperfusion. Circulation 1995;91:1872-85. [CrossRef]

19. Avanzas P, Quiles J, Lopez de Sa E, Sanchez A, Rubio R, Garcia E, et al. Neutrophil count and infarct size in patients with acute myocardial infarction. Int J Cardiol 2004;97:155-6. [CrossRef]

20. Kirtane AJ, Bui A, Murphy SA, Barron HV, Gibson CM. Association of peripheral neutrophilia with adverse angiographic outcomes in ST elevation myocardial infarction. Am J Cardiol 2004;93:532-6. [CrossRef]

21. Ommen SR, Gibbons RJ, Hodge DO, Thomson SP. Usefulness of the lymphocyte concentration as a prognostic marker in coronary artery disease. Am J Cardiol 1997;79:812-4. [CrossRef]

22. Ommen SR, Hodge DO, Rodeheffer RJ, McGregor CG, Thomson SP, Gibbons RJ. Predictive power of the relative lymphocyte 
concentration in patients with advanced heart failure. Circulation 1998;97:19-22. [CrossRef]

23. Takahashi M, Newburger JW. Kawasaki Syndrome (Mucocutaneous Lymph Node Syndrome). In: Allen HD, Driscoll DJ, Shaddy RE, Feltes TF, editors. Moss and Adams' Heart Disease in Infants, Children, and Adolescents: Including the Fetus and Young Adult. $7^{\text {th }}$ ed. Philadelphia: Lippincott Williams \& Wilkins; 2008:1242-55.

24. Takahashi K, Oharaseki T, Yokouchi Y, Naoe S, Saji T. Kawasaki disease: basic and pathological findings. Clin Exp Nephrol 2013:17:690-3. [CrossRef]

25. Suzuki A, Miyagawa-Tomita S, Komatsu K, Nishikawa T, Sakomura Y, Horie T, et al. Active remodeling of the coronary arterial lesions in the late phase of Kawasaki disease: immunohistochemical study. Circulation 2000;101:2935-41. [CrossRef]
26. Sonobe T, Kiyosawa N, Tsuchiya K, Aso S, Imada Y, Imai Y, et al. Prevalence of coronary artery abnormality in incomplete Kawasaki disease. Pediatr Int 2007;49:421-6. [CrossRef]

27. Aydin M, Tekin IO, Dogan SM, Yildirim N, Arasli M, Sayin $\mathrm{MR}$, et al. The levels of tumor necrosis factor-alpha and interleukin-6 in patients with isolated coronary artery ectasia. Mediators Inflamm 2009;106145. [CrossRef]

28. Kajinami K, Kasashima S, Oda Y, Koizumi J, Katsuda S, Mabuchi H. Coronary ectasia in familial hypercholesterolemia: a histopathological study regarding matrix metalloproteinases. Mod Pathol 1999;12:1174-80.

29. Li JJ, Li Z, Li J. Is any link between inflammation and coronary artery ectasia? Med Hypotheses 2007;69:678-83. [CrossRef]

30. Kalaycıoğlu E, Gökdeniz T, Aykan AC, Gül I, Boyacı F, Gürsoy $\mathrm{OM}$, et al. Comparison of neutrophil to lymphocyte ratio in patients with coronary artery ectasia versus patients with obstructive coronary artery disease. Kardiol Pol 2014;72:372-80. [CrossRef] 